\title{
Callynormine A, A New Marine Cyclic Peptide of a Novel Class
}

Nelly Berer ${ }^{\ddagger}$, Amira Rudi ${ }^{\ddagger}$, Israel Goldberg ${ }^{\ddagger}$, Yehuda Benayahu ${ }^{\dagger}$ and Yoel Kashman ${ }^{* *}$ School of Chemistry and Department of Zoology, Tel-Aviv University, Ramat Aviv

Email: kashman@post.tau.ac.il. 69978, Israel

* To whom correspondence should be addressed: Tel.: +972-3-6408419. Fax: +972-3-6409293.

${ }^{\ddagger}$ School of Chemistry, Tel-Aviv University.

${ }^{\dagger}$ Department of Zoology, Tel Aviv. 


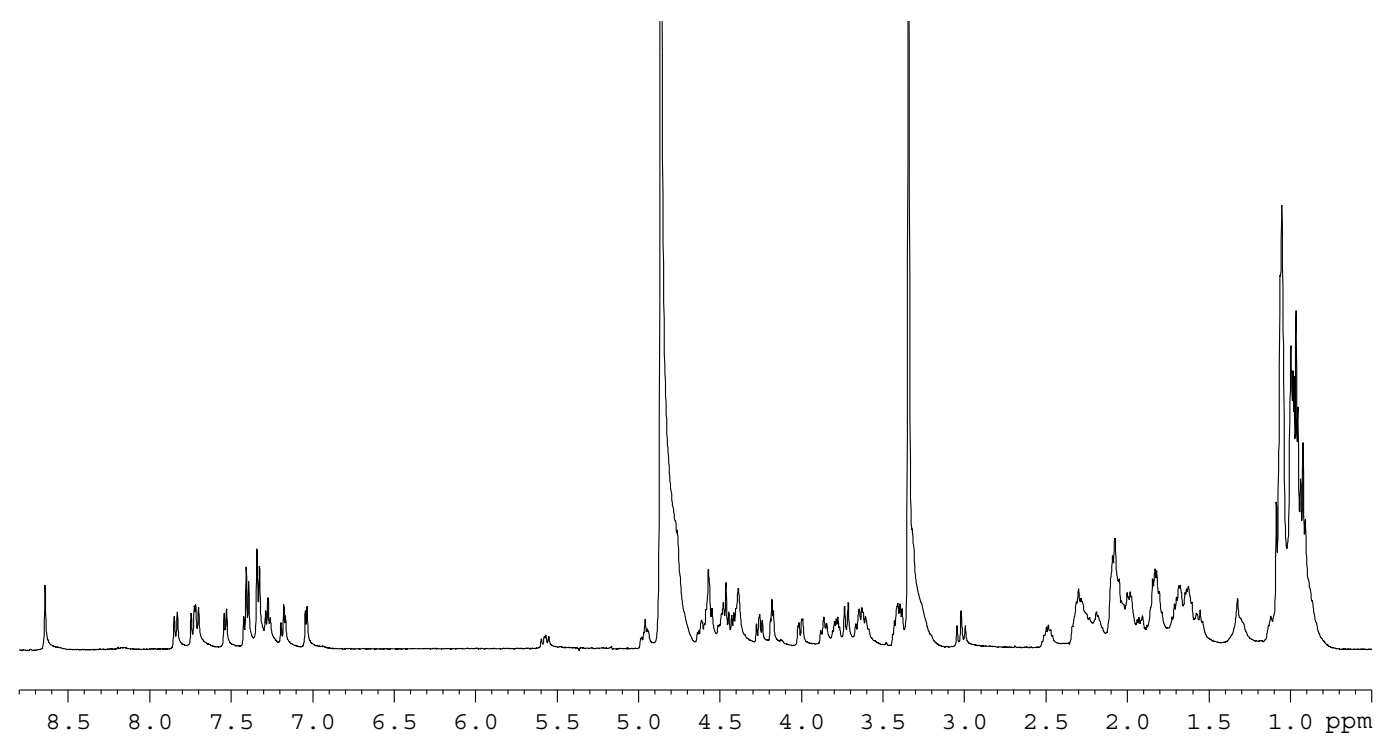

${ }^{1} \mathrm{H}-\mathrm{NMR}$ spectrum of $\mathbf{1}(500 \mathrm{MHz})$.



COSY spectrum of $\mathbf{1}(500 \mathrm{MHz})$. 


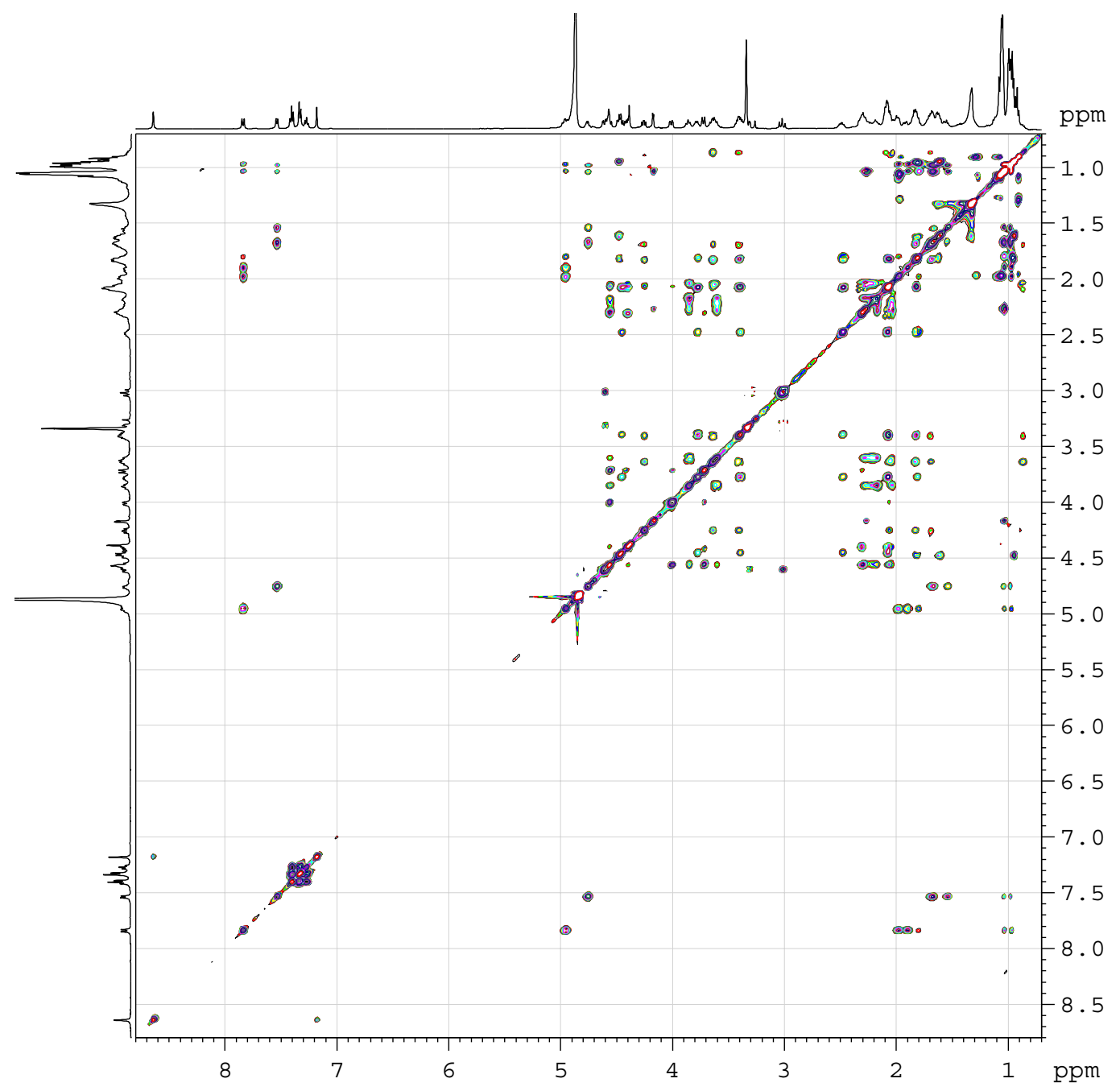

TOCSY spectrum of $\mathbf{1}(500 \mathrm{MHz})$. 